SOG I OLOGIA

ECONOMICA 
Serie: SOCIOLOGIA 


\section{Dr. FRIEDRICH FÜRSTENBERG}

Universidad Tubingen

\section{SOCIOLOGIA \\ ECONOMICA}

Traducción del

Prof. Ansgar Klein

y

Laura T. de Steinhauser

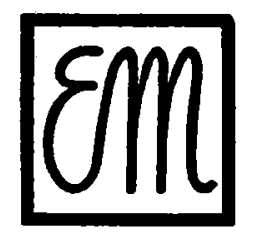

EDICIONES MANES

BUENOS AIRES

$\begin{array}{llll}1 & 9 & 6 & 3\end{array}$ 
Título de la edición original

\title{
WIRTSCHAFTSSOZIOLOGIE
}

(C) Walter de Gruyter \& Co.

Berlín - 1961

\author{
(C) Ediciones MANES S. C. A. - 1962 \\ Córdoba 1513 \\ Buenos Aires - Argentina
}

Impreso en Argentina.

Hecho el depósito

que marca la ley. 
NOTA DEL

EDITOR 

EDICIONES MANES, en el convencimiento de iniciar una serie de ediciones de obras de Economía relacionadas con el Derecho y la Sociología, ciencias intimamente ligadas dentro del estudio de Humanidades, se complace en comenzar con esta obra del profesor Friedrich Fürstenberg, su tarea.

Sucesivamente harâ entrega y en forma ininterrumpida de obras en los distintos campos de la Economía, esperando una positiva aceptación por parte de intelectuales, profesores, profesionales, empresarios y estudiosos de la Argentina y América Latina.

Buenos Aires, abril de 1963. 
